\title{
Microvascular blood flow response in the intestinal wall and the omentum during negative wound pressure therapy of the open abdomen
}

\author{
Joanna Hlebowicz • Johan Hansson • Sandra Lindstedt
}

Accepted: 5 September 2011 / Published online: 22 September 2011

(C) The Author(s) 2011. This article is published with open access at Springerlink.com

\begin{abstract}
Purpose Higher closure rates of the open abdomen have been reported with negative pressure wound therapy (NPWT) compared with other wound therapy techniques. However, the method has occasionally been associated with increased development of intestinal fistulae. The present study measures microvascular blood flow in the intestinal wall and the omentum before and during NPWT.

Methods Six pigs underwent midline incision and application of NPWT to the open abdomen. The microvascular blood flow in the underlying intestinal loop wall and the omentum was recorded before and after the application of NPWT of $-50,-70,-100,-120,-150$, and $-170 \mathrm{mmHg}$ respectively, using laser Doppler velocimetry.

Results A significant decrease in microvascular blood flow was seen in the intestinal wall during application of all negative pressures levels. The blood flow was $2.7( \pm 0.2)$ Perfusion Units (PU) before and $2.0( \pm 0.2)$ PU $(* p<0.05)$ after
\end{abstract}

\section{J. Hlebowicz}

Department of Medicine,

Lund University and Skåne University Hospital,

Lund, Sweden

\section{J. Hansson}

Institution of Surgical Sciences, Faculty of Medicine,

Uppsala University,

Uppsala, Sweden

\section{S. Lindstedt}

Department of Cardiothoracic Surgery,

Lund University and Skåne University Hospital,

Lund, Sweden

\section{S. Lindstedt $(\bowtie)$}

Department of Cardiothoracic Surgery, Heart and Lung Centre,

Lund University Hospital,

22185 Lund, Sweden

e-mail: sandra.lindstedt@skane.se application of $-50 \mathrm{mmHg}$, and $3.6( \pm 0.6) \mathrm{PU}$ before and $1.5( \pm 0.2) \mathrm{PU}(* * p<0.01)$ after application of $-170 \mathrm{mmHg}$. Conclusions In the present study, we show that negative pressures between -50 and $-170 \mathrm{mmHg}$ induce a significant decrease in the microvascular blood flow in the intestinal wall. The decrease in blood flow increased with the amount of negative pressure applied. One can only speculate that a longstanding decreased blood flow in the intestinal wall may induce ischemia and secondary necrosis in the intestinal wall, which, theoretically, could promote the development of intestinal fistulae. We believe that NPWT of the open abdomen is a very effective treatment but could probably be improved.

Keywords Negative pressure wound therapy - Open abdomen · Microvascular blood flow Intestinal wall . Omentum

\section{Introduction}

Laparostomy or open abdomen has developed over the last 20 years as a lifesaving intervention for surgical emergencies such as abdominal compartment syndrome, wound dehiscence, trauma, and intra-abdominal sepsis [1-5]. Primary goals of wound management include avoidance of mechanical contamination of abdominal viscera, active removal of exudates, third space fluid loss estimation, infection control, and prevention of intestinal fistulae [6]. Various materials have been used to dress the open abdomen including intravenous fluid bags, Goretex, Bogota bags, and sandwiched gauze dressings [7]. Negative pressure wound therapy (NPWT) applies the principle of topical negative pressure (TNP) through the use of suction tubing and an occlusive dressing (the vacuum pack method) to 
divert contaminated effluent away from the peritoneal cavity. Temporary closure of the abdominal cavity with plastic bags, silicone sheets, absorbable, and non-absorbable meshes sutured to the fascial or skin edges do not facilitate definitive closure of the abdominal wall. Skin-only closure or splitthickness skin grafting may be used for covering the bowels and omentum $[1,7,8]$. The major drawback with these techniques is the formation of extensive ventral hernias that have to be dealt with later. The use of airtight dressings and vacuum therapy for handling the open abdomen has improved care and increased the possibility for closure of the open abdomen. However, the method has occasionally been associated with increased development of intestinal fistulae and enteroatmospheric fistulae [9-13]. The mechanical effects of NPWT may result in ischemia, which in turn may promote the development of fistulae.

There have been several reports over the years showing excellent clinical results of NPWT [6, 9, 11, 14-18]. However, in November 2009, the Food and Drug Administration (FDA), USA, issued a preliminary warning regarding incoming reports of rare but serious complications associated with the use of NPWT. The warning was issued after the FDA received reports of six deaths and 77 injuries associated with NPWT systems over the past 2 years. Bleeding was the most serious complication and was reported in 6 death and 17 injury cases. Twenty-seven reports indicated infection from original open infected wounds or from retention of dressing pieces in the wound. Retention of foam dressing pieces and foam adhering to tissues or imbedded in the wound were noted in 32 injury reports. The majority of these patients required surgical procedures for removal of the retained pieces, wound debridement, and treatment of wound dehiscence, as well as additional hospitalization and antibiotic therapy.

In the present study, we examine whether NPWT applied in the open abdomen induces any changes in the microvascular blood flow in the intestines or in the omentum. Theoretically, ischemia and secondary necrosis in the intestinal wall and the omentum could promote the development of intestinal fistulae and enteroatmospheric fistulae. We measured the microvascular blood flow using fiber optic laser Doppler probes. Blood flow changes were studied in the omentum and in the intestinal wall during exposure to TPN between -50 and $-170 \mathrm{mmHg}$. To our knowledge, no such study has previously been conducted.

\section{Materials and methods}

\section{Experimental animals}

Six domestic pigs of both genders with a median weight of $60 \mathrm{~kg}$ were used. The animals were fasted overnight but given free access to water. The investigation complied with the "Guide for the Care and Use of Laboratory Animals" as recommended by the U.S. National Institutes of Health and published by the National Academies Press (1996).

\section{Anesthesia}

All the animals were pre-medicated intramuscularly with ketamine $(30 \mathrm{mg} / \mathrm{kg})$ before being brought into the laboratory. Before commencing surgery, sodium thiopental $(5 \mathrm{mg} / \mathrm{kg})$, atropine $(0.02 \mathrm{mg} / \mathrm{kg})$, and pancuronium $(0.5 \mathrm{mg} / \mathrm{kg})$ were given intravenously. Intubation was performed with a Portex endotracheal tube $(7.5 \mathrm{~mm}$ internal diameter, Medcompare, South San Francisco, CA). A servo-ventilator (Siemens Elema 300A, Stockholm, Sweden) was used for mechanical ventilation throughout the experiments. The ventilator settings used were: minute volume $=$ $100 \mathrm{ml} / \mathrm{kg}, \mathrm{FiO}_{2}=0.5$, breathing frequency $=16$ breaths $/$ minute, and positive end expiratory pressure $=5 \mathrm{~cm} \mathrm{H}_{2} \mathrm{O}$. Anesthesia and muscular paralysis were maintained by continuous intravenous infusion of $8-10 \mathrm{mg} / \mathrm{kg} /$ hour propofol (Diprivan, AstraZeneca, Sweden), $0.15 \mathrm{mg} / \mathrm{kg} / \mathrm{hour}$ fentanyl (Leptanal, Lilly, France), and $0.6 \mathrm{mg} / \mathrm{kg} / \mathrm{hour}$ pancuronium (Pavulon, Organon Teknika, Boxtel, the Netherlands).

\section{Data acquisition}

Heart frequency and ventilator parameters were recorded throughout the experiments.

\section{Surgical procedure}

A 30-cm long midline incision was performed on each pig. The V.A.C. ${ }^{\circledR}$ Granu Foam ${ }^{\mathrm{TM}}$ abdominal dressing system (KCI, San Antonio, TX) was used. The visceral protective layer was cut to an appropriate size, extending into the paracolic gutters on both sides (about $35 \mathrm{~cm}$ wide and $35 \mathrm{~cm}$ long). A layer of polyurethane Granu Foam was placed on top of the visceral protective layer between the edges of the wound. The wound was covered with selfadhesive polyethylene drape, a track pad was inserted through the drape (all from V.A.C., KCI, San Antonio, TX), and then connected to a continuous vacuum source.

Microvascular blood flow was measured by LDV (Transonic ${ }^{\circledR}$ Laser Doppler Monitor, BLF21, Maastricht, the Netherlands) using a technique that quantifies the sum of the motion of the red blood cells in a specific volume. This method is applied extensively in plastic surgery procedures and employs a fiberoptic probe carrying a beam of light. Light impinging on cells in motion undergoes a change in wavelength (Doppler shift) while light impinging on static objects remains unchanged. The magnitude and 
frequency distributions of the changes are directly related to the number and velocity of red blood cells. The information is collected by a returning fiber, converted into an electronic signal and analyzed [19].

Laser Doppler probes were inserted into the omentum and also into the intestinal wall of the ileac loop, which was sutured to the inner surface center of the visceral protective layer. The probe location was confirmed following completion of the experiments (Fig. 1). The experimental design is shown in Fig. 2.

\section{Experimental protocol}

The microvascular blood flow was measured continuously by the laser Doppler filament probes. After the setup, a restoration time of $30 \mathrm{~min}$ was allowed, where no negative pressure was applied to the NPWT dressing. Recordings were made before NPWT (baseline $=0 \mathrm{mmHg}$ ) and during exposure to NPWT at $-50-70,-100,-120,-150$, and $-170 \mathrm{mmHg}$. Baseline was restored between each pressure setting. The restoration time between each setting was $30 \mathrm{~min}$. The pressures were applied in random order to prevent systematic effects.

\section{Calculations and statistics}

Laser Doppler velocimetry measurements were performed on six pigs. The output was recorded continuously using the Transonic ${ }^{\circledR}$ Laser Doppler Monitor. Microvascular blood flow was expressed in terms of perfusion units (PU). Calculations and statistical analysis were performed using GraphPad 5.0 software (San Diego, CA). The Mann-Whitney test was used when comparing two groups and the Kruskal-Wallis test with Dunn's test for multiple comparisons when comparing three groups or more. Significance was defined as $p<0.05$ (*), $^{*}<$

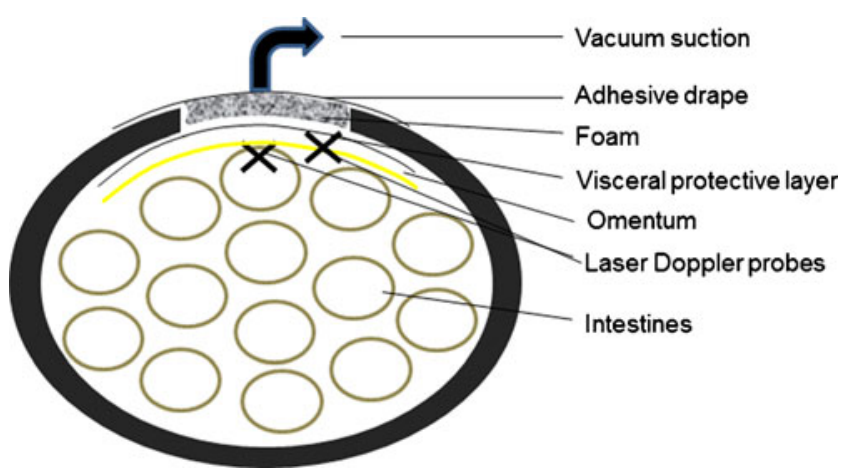

Fig. 1 The figure shows a schematic drawing of the negative wound pressure therapy of the abdomen (vacuum pack method) setup and the location of the laser Doppler probes. The part of the intestinal wall and the part of the omentum where the blood flow was measured was sutured to the inner surface of the visceral protective layer. All probe locations were controlled after every experiment $\left.0.01{ }^{(* *}\right), p<0.001(* * *)$, and $p>0.05$ (not significant, n.s.). The values given are the mean of ten measurements and the standard error on the mean (SEM).

\section{Results}

Intestinal wall

The microvascular blood flow was measured in the small intestinal loop of the abdomen, sutured to the dressing. The results are shown in Fig. 3. The blood flow was $2.7( \pm 0.2)$ PU before and $2.0( \pm 0.2)$ PU $(* p<0.05)$ after application of $-50 \mathrm{mmHg}$, and $3.8( \pm 0.4) \mathrm{PU}$ before and 2,5 $( \pm 0.2) \mathrm{PU}$ $\left({ }^{*} p<0.05\right)$ after application of $-70 \mathrm{mmHg}$, and $4.0( \pm 0.6)$ PU before and $2.7( \pm 0.4) \mathrm{PU}(* * p<0.01)$, after application of $-100 \mathrm{mmHg}$, and $3.8 \mathrm{PU}( \pm 0.6)$ before and $2.3( \pm 0.3)$ PU $(* * p<0.01)$ after application of $-120 \mathrm{mmHg}$, and 3.5 $( \pm 0.6)$ PU before and $1.9( \pm 0.3)$ PU $(* * p<0.01)$ after application of $-150 \mathrm{mmHg}$, and $3.6( \pm 0.6) \mathrm{PU}$ before and 1.5 $( \pm 0.2) \mathrm{PU}(* * p<0.01)$ after application of $-170 \mathrm{mmHg}$.

The omentum

The microvascular blood flow was measured in the omentum, sutured to the dressing. The results are shown in Fig. 4. The blood flow was $1.4( \pm 0.1)$ PU before and 1.3 $( \pm 0.1)$ PU $(p>0.05)$ after application of $-50 \mathrm{mmHg}$, and 1.6 $( \pm 0.1)$ PU before and $1.5( \pm 0.2)$ PU $(p>0.05)$ after application of $-70 \mathrm{mmHg}$, and $1.4( \pm 0.2)$ PU before and $1.2( \pm 0.2) \mathrm{PU}(p>0.05)$, after application of $-100 \mathrm{mmHg}$, and 1.4 PU $( \pm 0.1)$ before and $1.2( \pm 0.2) \mathrm{PU}(p>0.05)$ after application of $-120 \mathrm{mmHg}$, and $1.4( \pm 0.1) \mathrm{PU}$ before and $1.1( \pm 0.1)$ PU $(* p<0.05)$ after application of $-150 \mathrm{mmHg}$, and $1.4( \pm 0.1)$ PU before and $0.9( \pm 0.1)$ PU $(* p<0.05)$ after application of $-170 \mathrm{mmHg}$.

\section{Discussion}

The management of open abdomen in severely injured patients or those with serious intra-abdominal infections represent a significant challenge to the surgeon and may include treatment of abdominal compartment syndrome, effects on respiration, cardiovascular and renal function, and even "damage control" laparatomy. Life-sustaining emergency operations in patients with severe abdominal injuries are often accompanied by visceral edema, retroperitoneal hematoma, or packing of the abdominal cavity. The pressure of forced abdominal wall closure or an abdominal infection may lead to ischemia and necrosis of the abdominal fascia. The latter may result in abdominal rupture with subsequent development of an abdominal wall 
Fig. 2 Photograph of the experimental setup, with the laser Doppler machine, and the laser Doppler filament probes used to measure blood flow of the small intestinal wall
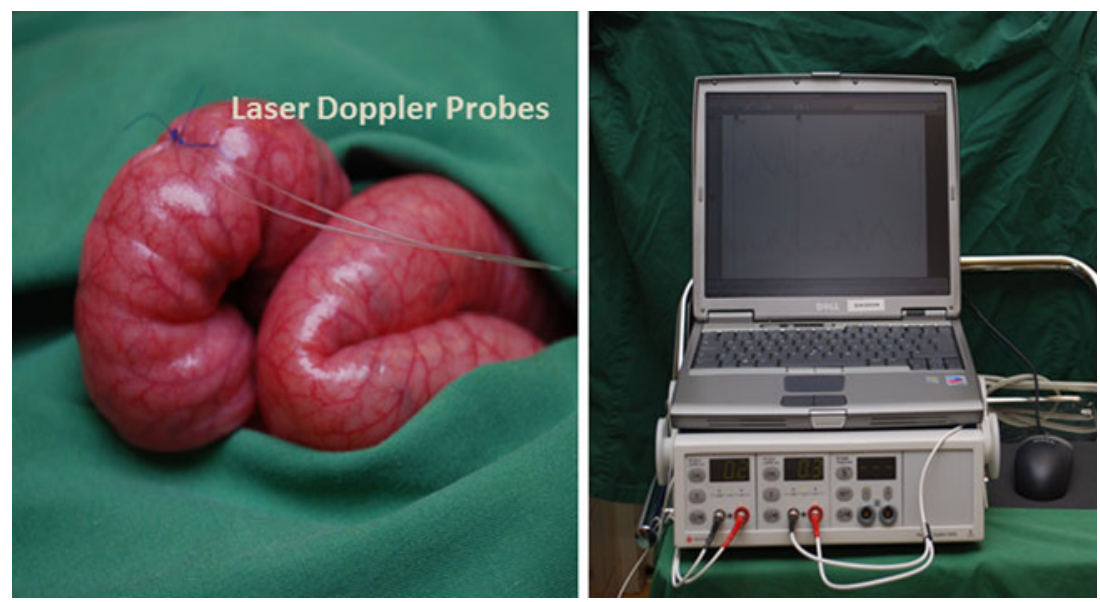

hernia $[1-3,5,14,20-24]$. With the development of damage control techniques and the understanding of abdominal compartment syndrome, the open abdomen has become more commonplace. If the abdomen is not closed in the early postoperative period, the combination of adhesions and fascial retraction frequently make primary fascial closure impossible, and creation of a planned ventral hernia is often required. NPWT employs suction applied to
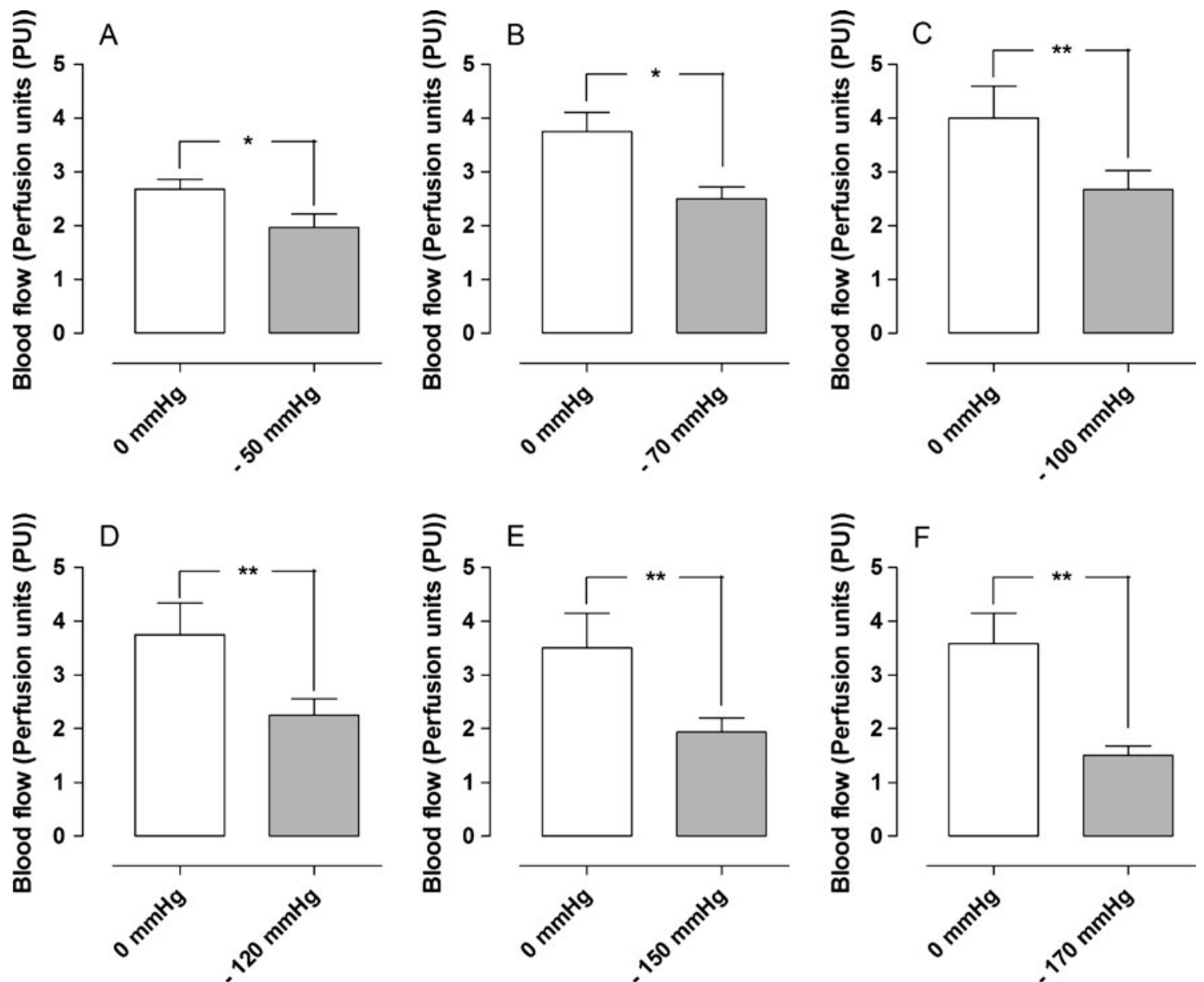

Fig. 3 Microvascular blood flow measured using laser Doppler velocimetry in intestinal wall exposed to NPWT of a $-50 \mathrm{mmHg}$, b $-70 \mathrm{mmHg}, \mathbf{c}-100 \mathrm{mmHg}, \mathbf{d}-120 \mathrm{mmHg}$, e $-150 \mathrm{mmHg}$,

loop, which had direct contact with the center of the VAC pack bandage. Significance was defined as ${ }^{*} p<0.05,{ }^{* *} p<0.01,{ }^{* * *} p<$ 0.001 and $p>0.05$ (not significant, n.s.). Values are presented as f $-170 \mathrm{mmHg}$. The measurements were performed in an intestinal means \pm the standard error on the mean (SEM) of six experiments 

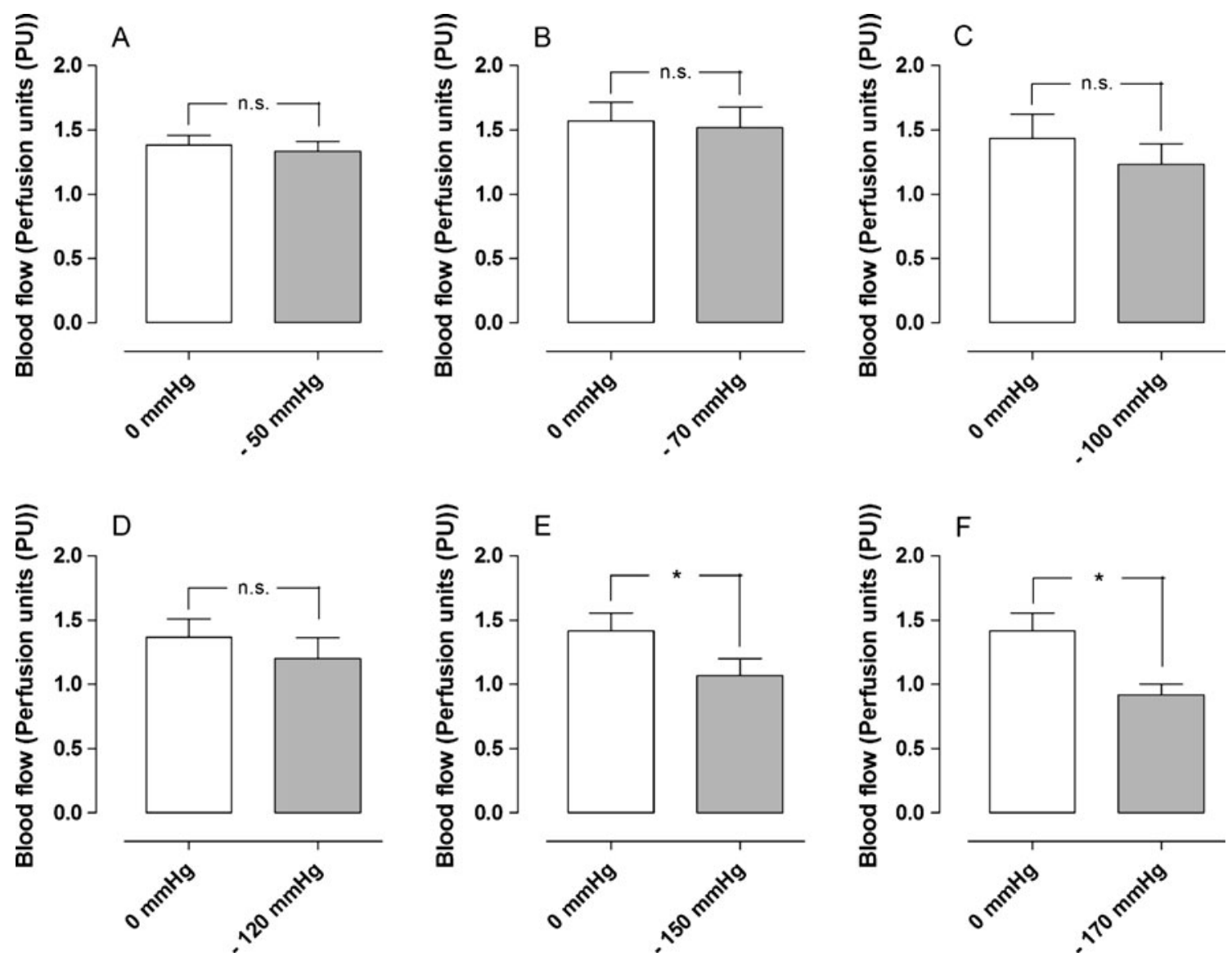

Fig. 4 Microvascular blood flow measured using laser Doppler velocimetry in omentum exposed to NPWT of $\mathbf{a}-50 \mathrm{mmHg}, \mathbf{b}-70 \mathrm{mmHg}$, c $-100 \mathrm{mmHg}$, d) $-120 \mathrm{mmHg}$, e) $-150 \mathrm{mmHg}$, f) $-170 \mathrm{mmHg}$. The measurements were performed in the omentum, which had direct

a large polyurethane sponge under an occlusive dressing in the wound and allows for constant medial traction of the abdominal fascia. The technique also allows the abdominal wall to move freely toward the midline without the interference of adhesions between the bowel and the abdominal wall. NPWT has a drainage effect, facilitating the reduction of peritoneal fluid and bacteria. Higher closure rates of the abdomen have been reported with NPWT compared with other techniques $[4,6,14,15,24$, 25]. However, the method has occasionally been associated with increased development of intestinal fistulae and enteroatmospheric fistulae $[6,10,12,13,18,26,27]$. The mechanical effects of NPWT may result in ischemia, which in turn may promote the development of fistulae.

In the present study, we show that the blood flow in the intestinal wall significantly decreases at all levels of NPWT between -50 and $-170 \mathrm{mmHg}$. The results also indicate that the decrease in blood flow escalates according to the force used. For example, the decrease in intestinal wall blood flow was greater when using -170 than $-150 \mathrm{mmHg}$, and the decrease in intestinal wall blood flow was greater contact with the center of the VAC pack bandage. Significance was defined as ${ }^{*} p<0.05,{ }^{* *} p<0.01,{ }^{* * *} p<0.001$, and $p>0.05$ (not significant, n.s.). Values are presented as means \pm the standard error on the mean (SEM) of six experiments

when using -150 than $-120 \mathrm{mmHg}$ and so on. The blood flow in the omentum was unchanged during application of NPWT of -50 and $-70 \mathrm{mmHg}$ but was significantly decreased during application of NPWT between -100 and $-170 \mathrm{mmHg}$. The decrease in blood flow increased with the amount of negative pressure applied. After application of the NPWT dressing, the animal was untouched for $30 \mathrm{~min}$ (0 $\mathrm{mmHg}$ was applied); the microvascular blood flow of the small intestinal wall and the omentum were continuously measured. Steady state was established after 30-60 s. The decrease in blood flow could be witnessed instantly after the negative pressure was applied, steady state was seen after 30-60 s, and recordings were made after approximately $15 \mathrm{~min}$. No changes in microvascular blood flow in the intestinal wall and the omentum was seen after steady state was established in this time frame.

We have previously shown that NPWT induces an increase in the blood flow of the peristernal soft tissue (i.e., skeletal muscular and subcutaneous tissue) and also that the change is related to local effects, since the blood flow at a distance of $4.5 \mathrm{~cm}$ from the wound edge was not affected by 
the negative pressure. The blood flow increased with elevated subatmospheric pressure in both subcutaneous and skeletal muscular tissue. When the area under the flow-distance curve was analyzed, covering 0.5 to $4.5 \mathrm{~cm}$ from the wound edge, a maximal net increase in blood flow was observed at -75 and $-100 \mathrm{mmHg}$, in muscular tissue. A difference in the profiles of the blood flow responses was observed between the subcutaneous and the muscular tissue. The distance from the wound edge to the point at which the blood flow increased was shorter in muscular tissue than in subcutaneous tissue. This may indicate that pressure is transduced differently in soft and dense tissue, and a less dense tissue collapses more easily when affected by pressure. In the immediate proximity of the wound edge, a zone of relative hypoperfusion was observed. This zone was larger at high negative pressures and was especially prominent in subcutaneous tissue. The size of the hypoperfused zone depended on the pressure applied and expanded with increasing negative pressure. In summary, the changes in the peristernal wound blood flow caused by TNP vary with the distance from the wound edge. A few centimeters away from the wound edge, the blood flow increased when subatmospheric pressure was applied. Conversely, in the immediate proximity of the wound, the negative pressure induced relative hypoperfusion [28]. Theoretically, these physiological courses of events may also appear in the intestinal wall and in the omentum during exposure to TNP. Subsequently, a large force of NPWT could theoretically induce a large zone of ischemia in the intestinal wall and in the omentum that are in close contact with the VAC pack dressing and could lead to the development of intestinal fistulae.

Another explanation of the present study result may be that the NPWT of the open abdomen creates a form of hernia between the wound edges, and the hernia may increase with the amount of NPWT applied. A serious complication associated with the use of NPWT in cardiac surgery is right ventricle rupture, often resulting in death $[29,30]$. We have previously identified the cause of heart rupture in pigs using magnetic resonance imaging. The heart was shown to be drawn up towards the thoracic wall; the right ventricle bulged into the space between the sternal edges, and the sharp edges of the sternum protruded into the anterior surface of the heart [31]. Placing multiple layers of paraffin gauze over the anterior portion of the heart did not prevent deformation of the heart. However, these events could be prevented by inserting a flexible rigid plastic disc between the anterior part of the heart and the inside of the thoracic wall [32]. When using NPWT in the treatment of the open abdomen, it is possible that a similar mechanism occurs, i.e., bulging of the small intestines into the space between the wound edges, which may in part explain the ischemia seen in the underlying intestinal wall during NPWT of the open abdomen. In future studies, it would be of interest to study the intestinal microvascular blood flow in intestinal loops close to the anterior abdominal wall that are in contact with the visceral protective layer; if no or less decrease in blood flow is seen, the hypothesis of a mechanic hernia is strengthened.

\section{Conclusion}

In the present study, we show that applying negative pressure wound therapy to the open abdomen induces ischemia in the small intestines and the omentum. We have also shown that the decrease in blood flow increased with the amount of negative pressure applied. We speculate that a longstanding decreased blood flow in the intestinal wall may induce ischemia and secondary necrosis in the intestinal wall, which could promote the development of intestinal and enteroatmospheric fistulae. It is, however, uncertain what kind of clinical aspects these findings might have. Furthermore, we believe that NPWT of the open abdomen is a very effective treatment, mainly by its draining effects, but the treatment could probably be improved. We speculate that a kind of protective disc over the intestines could protect from local ischemia but still provide effective drainage. Further experimental studies have to be conducted.

Open Access This article is distributed under the terms of the Creative Commons Attribution Noncommercial License which permits any noncommercial use, distribution, and reproduction in any medium, provided the original author(s) and source are credited.

\section{References}

1. Schecter WP, Ivatury RR, Rotondo MF et al (2006) Open abdomen after trauma and abdominal sepsis: a strategy for management. J Am Coll Surg 203:390-396

2. Swan MC, Banwell PE (2005) The open abdomen: aetiology, classification and current management strategies. J Wound Care $14: 7-11$

3. Deenichin GP (2008) Abdominal compartment syndrome. Surg Today 38:5-19

4. Acosta S, Bjarnason T, Petersson U et al (2011) Multicentre prospective study of fascial closure rate after open abdomen with vacuum and mesh-mediated fascial traction. Br J Surg 98:735-743

5. Cheatham ML, Safcsak K (2010) Is the evolving management of intra-abdominal hypertension and abdominal compartment syndrome improving survival? Crit Care Med 38:402-407

6. Stevens P (2009) Vacuum-assisted closure of laparostomy wounds: a critical review of the literature. Int Wound J 6:259-266

7. Navsaria PH, Bunting M, Omoshoro-Jones J et al (2003) Temporary closure of open abdominal wounds by the modified sandwich-vacuum pack technique. Br J Surg 90:718-722

8. Schachtrupp A, Fackeldey V, Klinge U et al (2002) Temporary closure of the abdominal wall (laparostomy). Hernia 6:155-162 
9. Amin AI, Shaikh IA (2009) Topical negative pressure in managing severe peritonitis: a positive contribution? World J Gastroenterol 15:3394-3397

10. Becker HP, Willms A, Schwab R (2007) Small bowel fistulas and the open abdomen. Scand J Surg 96:263-271

11. DeFranzo AJ, Argenta L (2006) Vacuum-assisted closure for the treatment of abdominal wounds. Clin Plast Surg 33:213224, vi

12. Draus JM Jr, Huss SA, Harty NJ et al (2006) Enterocutaneous fistula: are treatments improving? Surgery 140:570-576, discussion 576-578

13. Falconi M, Pederzoli P (2001) The relevance of gastrointestinal fistulae in clinical practice: a review. Gut 49(Suppl 4): iv2-iv10

14. Cheatham ML, Malbrain ML, Kirkpatrick A et al (2007) Results from the International Conference of Experts on Intra-abdominal Hypertension and Abdominal Compartment Syndrome. II. Recommendations. Intensive Care Med 33:951-962

15. Perez D, Wildi S, Demartines N et al (2007) Prospective evaluation of vacuum-assisted closure in abdominal compartment syndrome and severe abdominal sepsis. J Am Coll Surg 205:586-592

16. Petersson U, Acosta S, Bjorck M (2007) Vacuum-assisted wound closure and mesh-mediated fascial traction-a novel technique for late closure of the open abdomen. World J Surg 31:2133-2137

17. Shaikh IA, Ballard-Wilson A, Yalamarthi S et al (2009) Use of topical negative pressure 'TNP' in assisted abdominal closure does not lead to high incidence of enteric fistulae. Colorectal Dis 12:931-934

18. Ubbink DT, Westerbos SJ, Nelson EA et al (2008) A systematic review of topical negative pressure therapy for acute and chronic wounds. Br J Surg 95:685-692

19. Zografos GC, Martis K, Morris DL (1992) Laser Doppler flowmetry in evaluation of cutaneous wound blood flow using various suturing techniques. Ann Surg 215:266-268

20. Bee TK, Croce MA, Magnotti LJ et al (2008) Temporary abdominal closure techniques: a prospective randomized trial comparing polyglactin 910 mesh and vacuum-assisted closure. J Trauma 65:337-342, discussion 342-334
21. Bjorck M, Bruhin A, Cheatham M et al (2009) Classificationimportant step to improve management of patients with an open abdomen. World J Surg 33:1154-1157

22. Cheatham ML (2009) Nonoperative management of intraabdominal hypertension and abdominal compartment syndrome. World J Surg 33:1116-1122

23. Kaplan M (2004) Managing the open abdomen. Ostomy Wound Manage 50, C2, 1-8, quiz $1 \mathrm{p}$ following 8

24. Malbrain ML, De laet I, Cheatham M (2007) Consensus conference definitions and recommendations on intra-abdominal hypertension (IAH) and the abdominal compartment syndrome (ACS) - the long road to the final publications, how did we get there? Acta Clin Belg Suppl (1):44-59

25. Svensson S, Monsen C, Kolbel T et al (2008) Predictors for outcome after vacuum assisted closure therapy of peri-vascular surgical site infections in the groin. Eur J Vasc Endovasc Surg 36:84-89

26. Evenson AR, Fischer JE (2006) Current management of enterocutaneous fistula. J Gastrointest Surg 10:455-464

27. Evenson RA, Fischer JE (2006) Treatment of enteric fistula in open abdomen. Chirurg 77:594-601

28. Wackenfors A, Gustafsson R, Sjogren J et al (2005) Blood flow responses in the peristernal thoracic wall during vacuum-assisted closure therapy. Ann Thorac Surg 79:1724-1730, discussion $1730-1721$

29. Abu-Omar Y, Naik MJ, Catarino PA et al (2003) Right ventricular rupture during use of high-pressure suction drainage in the management of poststernotomy mediastinitis. Ann Thorac Surg 76:974, author reply 974-975

30. Khoynezhad A, Abbas G, Palazzo RS et al (2004) Spontaneous right ventricular disruption following treatment of sternal infection. J Card Surg 19:74-78

31. Malmsjo M, Petzina R, Ugander M et al (2009) Preventing heart injury during negative pressure wound therapy in cardiac surgery: assessment using real-time magnetic resonance imaging. J Thorac Cardiovasc Surg 138:712-717

32. Petzina R, Ugander M, Gustafsson L et al (2007) Hemodynamic effects of vacuum-assisted closure therapy in cardiac surgery: assessment using magnetic resonance imaging. J Thorac Cardiovasc Surg 133:1154-1162 